\title{
Developmental and behavioural functions in young children with elevated blood lead levels
}

\section{J. M. RATCLIFFE}

From the Air Pollution Research Group, Imperial College of Science and Technology, London

SUMMARY Blood lead levels in some pre-schoolchildren living near a lead works and particularly in some children with fathers employed at the lead works showed evidence of increased exposure. Forty-seven of them took part three years later in a follow-up study of their developmental and behavioural functions. The children were aged between 4 and $5 \frac{1}{2}$ years and were closely matched for age, sex, social class, parental education, area, and length of residence. Only three children had moved house since their blood lead levels had been examined at two years of age; these levels ranged between 18 and $64 \mu \mathrm{g} / 100 \mathrm{ml}$. None of the children had clinical symptoms of plumbism. No statistically significant $(P \leq 0.05)$ differences were found on developmental and behavioural scores when the children were divided into two groups of $\leq 35 \mu \mathrm{g} / 100 \mathrm{ml}(\mathrm{n}=23)$ and $>35 \propto$ $\mu \mathrm{g} / 100 \mathrm{ml}(\mathrm{n}=24)$. The differences in scores were of the same order as those between boys and girls, which were themselves generally not significant. Behaviour ratings did not diffe $\vec{b} \overrightarrow{-}$ The variations in developmental skills were generally found to be more related to age an $\overrightarrow{\mathrm{A}}$ schooling; neither these factors nor the difference in sex was related to blood lead levels.

Children who have had an episode of acute 'clinical' lead poisoning, particularly those who have had encephalopathy, suffer neurological sequelae-such as, convulsions, visual impairment, hemiparesis, and other diffuse cortical injuries. These may result in impairment of motor control, speech and learning deficits; lower scholastic ability, and behavioural disturbances-such as, distractability and hyperactivity (Byers and Lord, 1943; Mellins and Jenkins, 1955; Smith et al., 1963; Perlstein and Attala, 1966).

Most cases of lead poisoning are diagnosed in children who are between the ages of one and five, very often at a time of pica, and when they are crawling or playing in contaminated streets and houses (Barltrop, 1968, 1973; Guinee, 1972; Lin-Fu, 1973; Guinee et al., 1975). Thus, the young child may be exposed to high concentrations of lead at a time when he may also be physiologically more susceptible than an adult to neurological damage. This may be due to central nervous system immaturity, the fact that he will have a relatively larger lead intake in proportion to body weight, and he may be less able to excrete lead and have a greater capacity to absorb it (King et al., 1972; Alexander et al., 1973).

There has been concern that there are a significant number of children who have lead burdens which, although are not high enough to require treatment, nevertheless may cause subtte neurological damage. Some circumstantial evidence 0 has been put forward by the finding of correlation between lead levels and mental retarda tion (Moncrieff et al., 1964; Gibson et al., 1967; David et al., 1976; Moore et al., 1977) and hyperactivity (David et al., 1972), but it is not known if lead is of primary aetiological significance. $\stackrel{\mathbb{Q}}{\triangle}$ Relatively few studies of neuropsychological func- $\vec{\overrightarrow{ }}$ tions in children with varying levels of exposure $\frac{\circ}{3}$ have been conducted (de la Burde and Choate, 1972, 1975; Kotok, 1972; Albert et al., 1974; Lansdown et al., 1974; Perino and Ernhart, 1974; Pueschel, 1974; Baloh et al., 1975; McNeil and $\stackrel{\odot}{\square}$ Ptasnik, 1975; Gregory et al., 1976; Landrigan et al., $\stackrel{?}{\circ}$ $1975,1976)$ and so far the results have been conflicting. This evidence will be discussed in the light of an investigation presented here on developmental and behavioural functions in a $\circ$ group of 47 four to five-year-old clinically asymptomatic children with a moderately high $\frac{7}{0}$ exposure to lead.

\section{Methods}

SELECTION AND CHARACTERISTICS OF

THE SAMPLE

Four hundred and sixty-five pre-schoolchildren $\stackrel{\circ}{\subset}$ took part in a survey on the environmental effect $\stackrel{\Phi}{\Phi}$ 
of a lead battery manufacturing works near Manchester, the results of which are published elsewhere (Elwood et al., 1977). The children of leadworkers, most of whom lived near the factory, together with a random sample of children who also lived in the proximity of the works (roughly within a three-mile radius) had a $0.2 \mathrm{ml}$ capillary blood sample taken by heel or finger prick; this was analysed by Delves' cup atomic absorption spectrophotometry. A second blood sample was taken if the first measurement was $\geqslant 50 \mu \mathrm{g} / 100 \mathrm{ml}$ blood; if the high level was confirmed the child was referred to a paediatrician and the general practitioner. In the three children for whom this was done there were no signs or symptoms of ill health and two of them are included in the present sample. Thus, all the children are considered to be clinically asymptotomatic.

About three years after the first study the children of leadworkers and other children in the area were again studied to assess their developmental and behavioural functions. The children chosen were those who had been two years old at the time of their first blood analysis and were born a maximum of 11 months apart. Their age range at testing was somewhat wider, from 49 to 67 months (mean $57 \cdot 3 \pm 4 \cdot 5$ ), because the tests were done by a single child psychologist during a period of about six months. To obtain a balanced distribution of lead levels and to match for sex, four boys and four girls were selected from each group in which their blood lead level had placed them at two-years old $\leqslant 25,26-30,31-35,36-40,41-45$, and $\geqslant$ $46 \mu \mathrm{g} / 100 \mathrm{ml}$; these constituted the final sample of 48 children (one girl eventually did not participate). Blood lead levels ranged between 18 and $64 \mu \mathrm{g} / 100$ $\mathrm{ml}$ with a mean of $36 \cdot 5 \pm 10 \cdot 4$. Replicate analyses were performed on $23 \%$ of the sample giving a mean difference of $4.5 \mu \mathrm{g} / 100 \mathrm{ml}$, and in these cases the average of the two results was taken; in three cases repeat blood samples were taken but only the first value was used. All blood samples were taken between August and December; there was no correlation between blood lead and the sampling date.

Nearly all the children had lived in the same house throughout their lives; three had moved locally within the previous two years. The families were from either social class IV or III manual (Registrar General, 1970). The duration and type of parental education was remarkably similar in nearly all cases. Before the children were tested the local health authority confirmed that in none was there a medical history of any organic condition, such as epilepsy, that might impair development.
TESTS

A child psychologist, who did not know to which group each child belonged, gave the following tests at the children's hospital with the child's mother present:

The Griffiths's mental development scales (Griffiths, 1967)

These consist of six subscales designed to evaluate gross locomotor, personal-social, hearing and speech, eye and hand co-ordination, performance, and practical reasoning development in children up to eight years of age. Each scale yields a subquotient which is age-standardised at 100 . The general quotient here is the arithmetic mean of the subquotients.

Part I of the Marianne Frostig developmental test of visual perception (Frostig et al., 1963)

This comprises line drawing between points and guidelines; a perceptional age equivalent for -fine motor co-ordination standardised for American children is obtained.

\section{A pegboard test}

The 10-peg board is that used by Annett to investigate manual preference and speed (Annett, 1970). The score was the mean time in seconds of three trials for the dominant and nondominant hand. Although speed does increase with age no adequate standardisation for this age range was available. No significant correlation with age was subsequently found for the age range of the children in this study.

A behaviour questionnaire was given to the parent. This was a slightly modified version of one developed by Richman and Graham (1971) for screening three-year-old children for behavioural difficulties. The 19 questions can score a maximum of 38 for a highly disturbed child and they include questions on concentration, activity, irritability, and control; these were also scored separately as a subrating with a maximum score of 8 . The questionnaire was also used to obtain information on such things as education, which was not available before testing. The child's behaviour during the examination was watched and any physical difficulties were noted.

\section{Results}

Before further analysis, the blood lead levels, age, and mean scores of boys and girls in each test were tested for significant differences by 2-tailed Student's $t$ tests (Table 1). Although boys did not perform as well as girls on the developmental 
Table 1 Results of developmental tests and difference between sexes

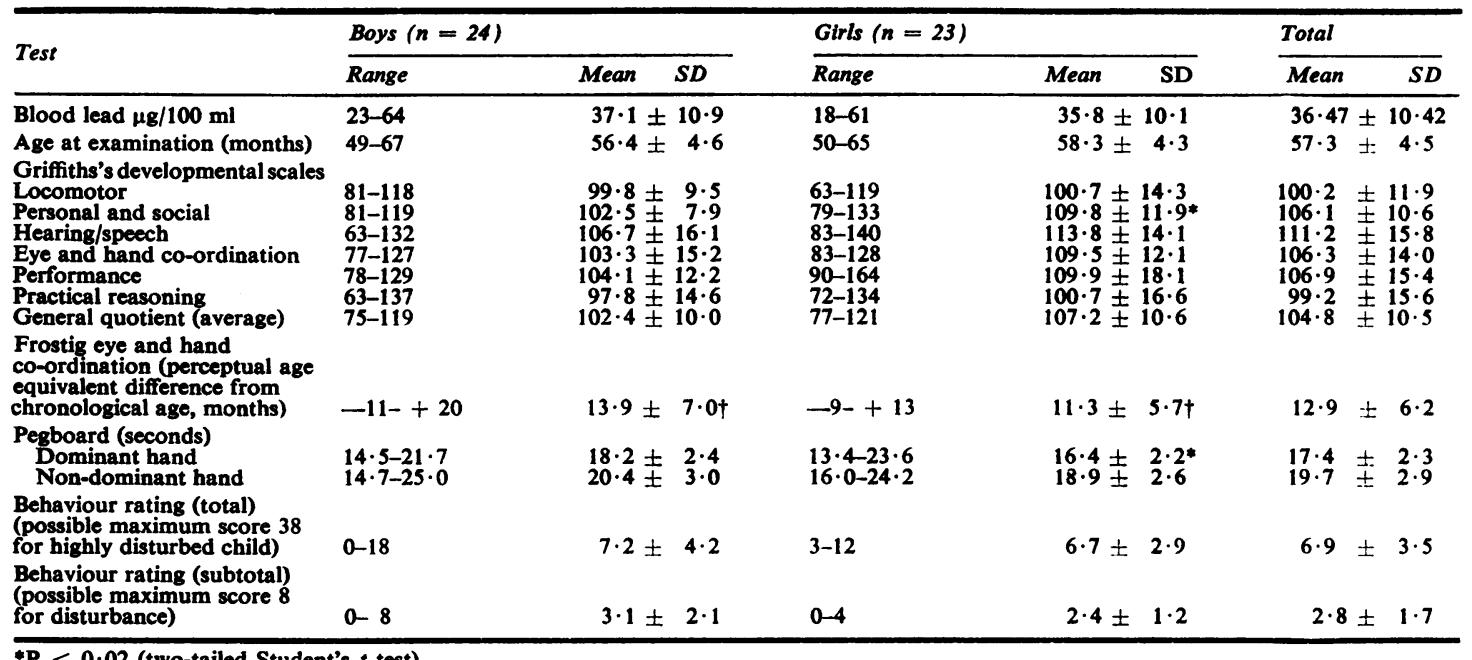

P $<0.02$ (two-tailed Student's $t$ test).

†Zero adjusted; standard mean $=+11$.

Table 2 Characteristics and results of developmental tests in children with 'high' and 'moderate' lead exposure

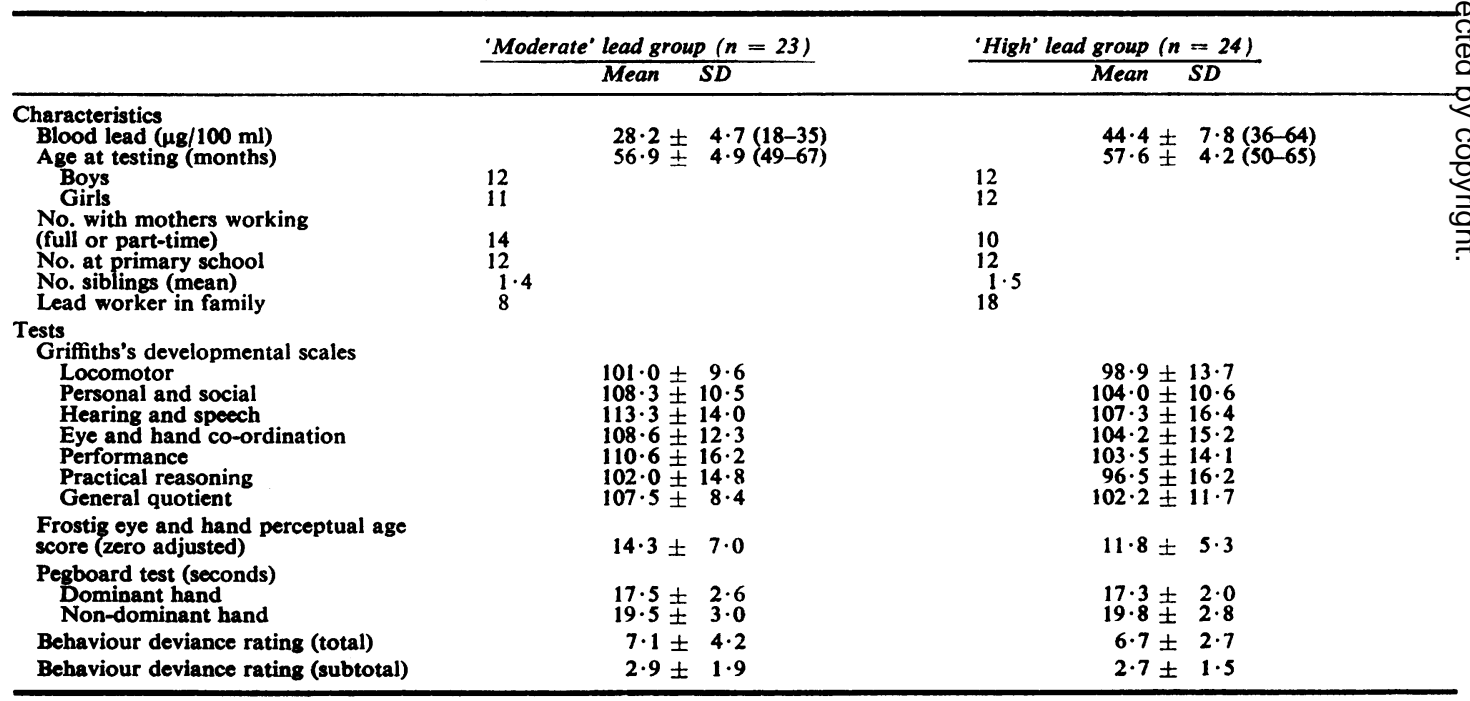

No significant differences $(P \leq \mathbf{0 . 0 5})$ were found between groups on any of the above tests.

scales, pegboard test, and behaviour rating, it was only on the personal-social scale and pegboard (dominant hand) test that there was a significant difference $(P<0.02)$. Because of the balanced sample and these findings the children were subsequently treated as a homogeneous group. Socioeconomic status, length of residence, and parental education were very similar throughout the group, and so these variables were not considered further.
The group was arbitrarily divided into a 'high' lead group ( $>35 \mu \mathrm{g} / 100 \mathrm{ml}, \mathrm{n}=24)$, and a 'moderate' lead group ( $\leq 35 \mu \mathrm{g} / 100 \mathrm{ml}, \mathrm{n}=23$ ). There were no significant differences between the two groups (by 2-tailed Student's $t$ tests) at the $95 \%$ level on any of the developmental or behavioural scores (Table 2).

To ascertain to what extent other measured 2 factors could explain the variation in scores between the children and if the putative effect of lead 
could be masked by these factors, all the data were analysed using a linear multiple regression model, with respect to age, schooling, mother working, sibling status, presence of lead worker in the family, and blood lead level. The factors which accounted for the greatest amount of variation in scores are presented in Table 3 . In cases where a 'block' variable (for example, primary school attendance) proved to be the most important factor in terms of the regression model, it was checked for statistical significance by a 2-tailed Student's $t$ test, and it is the results of these tests that are presented in Table 3.

Table 3 Results of analysis of factors accounting for differences in developmental and behavioural scores

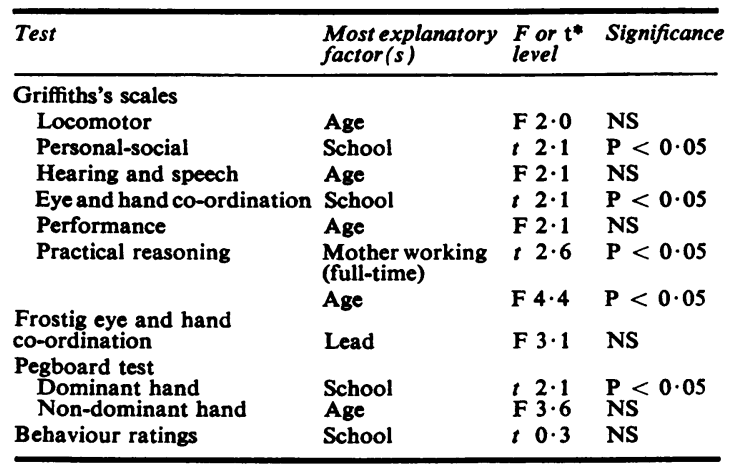

*Two-tailed Student's $t$ test.

A significant correlation was found between age and primary school attendance $(r=0.32, P<0.05)$; no statistically significant $(P$ $\leq \mathbf{0 . 0 5}$ ) correlations were found between paired combinations of any other of the above variables.

Only in the case of the Frostig eye-hand co-ordination score was the blood lead level the most explanatory factor of the variation in scores $(\mathrm{F} 3 \cdot 1, \mathrm{P}<0 \cdot 1)$, but this was not statistically significant. Otherwise, neither blood lead level nor the presence of a leadworker in the family irrespective of blood lead level, accounted more than marginally for variation in scores after these had been adjusted for age, schooling, and other variables. Blood lead level and a leadworker in the family were highly correlated ( $\mathrm{r} 0.5, \mathrm{P}<0.001)$, which is consistent with the results of the previous survey (Elwood et al., 1977) in which significant differences $(P<0.001)$ of $5.4 \mu \mathrm{g} / 100 \mathrm{ml}$ (two-yearold children) and $10 \cdot 1 \mu \mathrm{g} / 100 \mathrm{ml}$ (three-year-old children) were found between the mean blood levels of children of leadworkers and other children.

The variations in developmental scores appear to be principally related to age and attendance at primary school, in some cases to a statistically significant extent; these two variables are also significantly correlated with each other (r 0.32 , $P<0.05)$ so that it is not possible to distinguish their separate effects. This illustrates the importance of controlling for age, as the results indicate that even the use of 'age-standardised' tests such as the Griffiths's scales does not eliminate this factor, at least not in four to five-year-old children. There were no other significant correlations between paired combinations of blood lead, lead worker, age, sex, schooling, sibling status, and mother working, except those noted above.

It was noticeable that all but a tiny proportion of the variation in behavioural scores remained unexplained by the regression analysis. The questionnaire is primarily designed as a screening tool for behaviour deviance; the findings here suggested that since none of the children exhibited marked behavioural difficulties, the rating is not sufficiently sensitive to indicate small differences in behaviour that can be related to other factors; this may be owing to reporting bias of the parent or because of changes in the child's behavioural patterns at this age.

\section{Discussion}

Elevated blood lead levels over the range 18-64 $\mu \mathrm{g} / 100 \mathrm{ml}$ or the presence of a leadworker had no significant effect on a number of developmental and behavioural functions in this group of 4 to $5 \frac{1}{2}$ year-old children, even when other small differences between them were accounted for. Nevertheless as a group the children with blood lead levels between 35 and $64 \mu \mathrm{g} / 100 \mathrm{ml}$ consistently did slightly less well than those in the lower lead group.

Several points should be considered in interpreting these findings in relation to other studies in this field which may help to explain some of the reasons for the continuing controversy on the effect of 'subclinical' doses of lead in children. There are certain limitations to such studies that need to be recognised and there are differences between studies which preclude direct comparison and which may partially account for different results.

For example, most studies rely on the use of blood lead measurements as the index of exposure and it is on this basis that 'lead' and 'control' groups are usually defined. The criterion of exposure by which groups are defined, and the ranges of blood lead level or other measurements of lead in the body, may differ between studies. Kotok (1972) for example, included children who had blood lead levels of up to 137 (mean 81) $\mu \mathrm{g} / 100 \mathrm{ml}$, several of whom were symptomatic; de la Burdé and Choate (1972) similarly included 
children with lead levels of up to $100 \mu \mathrm{g} / 100 \mathrm{ml}$ with several other indices of excessive absorption although no 'obvious' symptoms. It can be misleading to compare the results of such studies with those on strictly 'asymptomatic' children with lower blood levels. This problem may be compounded by variations in the diagnosis of 'symptomatic' lead poisoning. Barltrop $(1968,1973)$ points out that early indications of toxicity may be non-specific or absent, and that even encephalopathy can occur without warning. Only four of the neuropsychological studies to date (Lansdown et al., 1974; Perino and Ernhart, 1974; Baloh et al., 1975; Landrigan et al., 1975) have been restricted to 'asymptomatic' children with levels of blood lead lower than $\simeq 70 \mu \mathrm{g} / 100 \mathrm{ml}$ (where the range is known) and only the study by Perino and Ernhart (1974) was exclusively conducted on preschoolchildren.

The accuracy of the blood lead analysis and the extent to which it reflects past exposure should be considered. A rigorous check on the accuracy of analysis of blood was carried out in the survey by Elwood et al. (1977) by means of replicates, standard bloods, and separate repeats of high $(\geq 50 \mu \mathrm{g} / 100 \mathrm{ml}$ ) samples. The results obtained in the survey by Elwood et al. (1977) using atomic absorption spectrophotometry tended to be slightly higher than those obtained with anodic stripping voltammetry, but the results were consistent with each other and so the difference does not affect the comparison between the children, all of whom were measured by the same method. As the children were tested three years after their blood had been analysed, this does not indicate total exposure up to the time of testing. Therefore one has to look for circumstantial evidence of a reasonably constant exposure; residence in the same house and presence of a leadworker since birth in nearly all relevant cases in the present survey can be taken to indicate this, but the actual lead intake during the same period remains unknown and this is an inevitable limitation to studies of this type; it is possible in this case only to determine whether correlations exist between present developmental skills and earlier blood lead levels.

Age, sex, and other differences between individuals in a study and between surveys can also limit the interpretation and comparison of results of these surveys. These factors can rarely be fully controlled, but are particularly important where high variability of the test parameters, such as eye and hand co-ordination, is combined with subtlety of the putative effect of lead.

In the present study, it has been noted that the variation in the developmental scores and behaviour could only partly be 'accounted for' by such factors as age, schooling, etc. and by none of these to a highly significant extent, and the lead level of the child generally made a negligible contribution to the observed variation. This could indicate that the sample size is either too small for statistically significant results, or that the population studied is similar with respect to the factors considered, and the variation in the scores is caused by other factors. For example, strong correlations have been found between environmental disruption, क and the quality of the mother-child relationship, $\vec{\circ}$ and developmental and behavioural problems (Mellins and Jenkins, 1955; Kotok, 1972; Lansdown et al., 1974; British Medical Journal, 1975). Parental $\stackrel{\odot}{\circ}$ intelligence and nutritional status may also affect $\stackrel{?}{?}$ development. It is not known if these factors differ $\stackrel{\omega}{\vec{\omega}}$ among the sample and if they are related to lead $\vec{A}$ levels. It is possible that the tests are insufficiently is sensitive and reliable. A high degree of correlation $\infty$

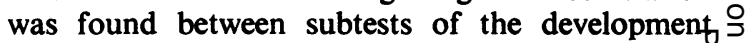
scales and between the three tests of eye $\rightarrow$ and motor co-ordination, which may be take as some measure of reliability. Testing was don $\bar{\varnothing}$ by one experienced person, thereby eliminating 3 tester bias which Gregory et al. (1976) found 은 accounted for a 15-point variation in IQ scores $\overrightarrow{0}$ As noted, the effect of age could be observed in some of the tests, including some which ate theoretically standardised in this respect. This illustrates the rapidity of development at this age as differences are noticeable over months, and it is important to control for age (and sex, see Table 1). 융 Such tests on younger children are less reliable $\stackrel{\mathbb{Q}}{\Omega}$ and have lower predictive ability than when applied $\overrightarrow{\overrightarrow{0}}$ to older children and should not be considered in 3 this capacity. Thus a follow-up study on the same population after, for example, five years would be useful.

In conclusion, the results of this study indicate ? that no significant effects on development of blood lead levels up to about $60 \mu \mathrm{g} / 100 \mathrm{ml}$ were observed in a sample of matched four to five-year-old $\delta$ children followed-up three years after their blood analyses. The difficulties and limitations of such 옥 studies where total exposure to lead is unknown $\rightarrow$ and where other factors may influence development, only some which can be eliminated by sample $N$ selection and statistical techniques, have been discussed. In the present case, it appears that age $O$ and schooling are more important factors in $\omega$ development, which emphasises the need for these factors to be properly taken into account in such $\stackrel{0}{\stackrel{C}{\odot}}$ studies. 
This survey was supported by the Chloride Group Ltd. The author would like to thank Professor R. S. Scorer of Imperial College, Dr W. J. Elwood, formerly Medical Officer of Health, Swinton and Pendlebury, M. B., Manchester, Dr D. Malcolm and Dr J. F. Taylor of the Chloride Group Ltd, and Dr N. Richman of the Hospital for Sick Children, Great Ormond Street, London, for their help. Finally I am indebted to Mrs M. A. Riley. of the Agnew Unit of the Royal Manchester Children's Hospital, who tested the children and without whose thorough work this survey would not have been possible.

Reprints from J. M. Ratcliffe, Air Pollution Research Group, Department of Mathematics, Imperial College of Science and Technology, London SW7 2BZ.

\section{References}

Albert, R. E., Shore, R. E., Sayers, A. J., Strehlow, C., Kneip, T. J., Pasternack, B. S., Friedhoff, A. J., Covan, F., and Cimino, J. A. (1974). Follow-up of children overexposed to lead. Environmental Health Perspectives, 7, 33-39.

Alexander, F. W., Delves, H. T., and Clayton, B. E. (1973). Uptake and excretion by children of lead and other contaminants. In Proceedings of the International Symposium on Environmental Health Aspects of Lead, Amsterdam 1972. Commission of the European Communities: Luxembourg.

Annett, M. (1970). The growth of manual preference and speed. British Journal of Psychology, 61, 545-558.

Baloh, R., Sturn, R., Green, B., and Glaser, G. (1975). Neuropsychological effects of chronic asymptomatic increased lead absorption. Archives of Neurology, 32, 326-330.

Barltrop, D. (1968). Lead poisoning in childhood. Postgraduate Medical Journal, 44, 537-548.

Barltrop, D. (1973). Sources and significance of environmental lead for children. In Proceedings of the International Symposium on Environmental Health Aspects of Lead, Amsterdam 1972. Commission of the European Communities: Luxembourg.

British Medical Journal (1975). Editorial: Hyperactivity in children. British Medical Journal, 4, 123-124.

Byers, R. K., and Lord, E. E. (1943). Late effects of lead poisoning on mental development. American Journal of Diseases of Children, 66, 471-474.

David O., Clark, J., and Voeller, K. (1972). Lead and hyperactivity. Lancet, 2, 900-903.

David, O., Hoffman, S., McGann, B., Sverd, J., and Clark, J. (1976). Low lead levels and mental retardation. Lancet, 2, 1376-1379.

de la Burde, B., and Choate, M. S. (1972). Does asymptomatic lead exposure in children have latent sequalae? Journal of Pediatrics, 81, 1088-1091.

de la Burdé, B., and Choate, M. S. (1975). Early asymptomatic lead exposure and development at school age. Journal of Pediatrics, 87, 638-642.
Elwood, W. J., Clayton, B. E., Cox, R. A., Delves, H. T., King, E., Malcolm, D., Ratcliffe, J. M., and Taylor, J. F. (1977). Lead in human blood and in the environment near a battery factory. British Journal of Preventive and Social Medicine, 31, 154-163.

Frostig, M., Meslow, P., Lefever, D. W., and Whittlesey, J. R. B. (1963). The Marianne Frostig Developmental Test of Visual Perception. 1963 Standardisation Monograph Supplement, 2-V19. Consulting Psychologists Press: California.

Gibson, S. L. M., Lam, C. N., McCrae, W. M., and Goldberg, A. (1967). Blood lead levels in normal and mentally deficient children. Archives of Disease in Childhood, 42, 573-578.

Gregory, R. J., Lehman, R. E., and Mohan, P. J. (1976). Intelligence Tests Results for Children With and Without Undue Lead Absorption. Shoshone Lead Health Project Report Work Summary, January 1976. Department of Health and Welfare: Idaho.

Griffiths, R. (1967). The Griffiths Mental Development Scales. Child Development Research Centre: London. Guinee, V. F. (1972). Lead poisoning. American Journal of Medicine, 52, 283-288.

Guinee, V. F., Davidow, B., and Tytun, A. (1975). Clinical and environmental correlations with blood lead levels of children in New York City. In Proceedings of the International Symposium on Recent Advances in the Assessment of the Health Effects of Environmental Pollution, Paris, June 1974. Commission of the European Communities: Luxembourg.

King, B. G., Schaplowsky, M. P. H., and McCabe, E. B. (1972). Occupational health and child lead poisoning: Mutual interests and special problems. American Journal of Public Health and the Nation's Health, 62, 1056-1059.

Kotok, D. (1972). Development of children with elevated blood lead levels. A controlled study. Journal of Pediatrics, 57, 57-61.

Landrigan, P. J., Baker, E. L., Feldman, R. G., Cox, D. H., Eden, K. V., Orenstein, W. A., Mather, J. A., Yankel, A. J., and von Lindern, I. H. (1976). Increased Lead Absorption with Anaemia and Slowed Nerve Conduction in Children Near a Lead Smelter. Shoshone Lead Health Project Report Work Summary, January 1976. Department of Health and Welfare: Idaho.

Landrigan, P. J., Whitworth, R. H., Baloh, R. W., Staehling, N. W., Barthel, W. F., and Rosenblum, B. F. (1975). Neuropsychological dysfunction in children with chronic low-level lead absorption. Lancet, 1, 708-712.

Lansdown, R. G., Shepherd, J., Clayton, B. E., Delves, H. T., Graham, P. J., and Turner, W. C. (1974). Blood-lead levels, behaviour and intelligence: A population study. Lancet, 1, 538-541.

Lin-Fu, J. S. (1973). Vulnerability of children to lead exposure and toxicity. New England Journal of Medicine, 289, 1229-1233; 1289-1293.

McNeil, J. L., and Ptasnik, J. A. (1975). Evaluation of long term effects of elevated blood lead concentration in asymptomatic children. In Proceedings of the International Symposium on Recent Advances in the 
Assessment of the Health Effects of Environmental Pollution, Paris, June 1974. Commission of the European Communities: Luxembourg.

Mellins, R. B., and Jenkins, C. D. (1955) Epidemiological and psychological study of lead poisoning in children. Journal of the American Medical Association, 158, 15-20.

Moncrieff, A. A., Koumides, O. P., Clayton, B. E., Patrick, A. D., Renwick, A. G. C., and Roberts, G. E. (1964). Lead poisoning in children. Archives of Disease in Childhood, 39, 1-13.

Moore, M. R., Meredith, P. A., and Goldberg, A. (1977). A retrospective analysis of blood-lead in mentally retarded children. Lancet, 1, 717-719.

Perino, J., and Ernhart, G. B. (1974). The relation of subclinical lead level to cognitive and sensorimotor impairment in black pre-schoolers. Journal of Learning Disabilities. 7, 26-31.
Perlstein, M. A., and Attala, R. (1966). Neurologic sequelae of plumbism. Clinical Pediatrics. 5, 292-298.

Pueschel, S. (1974). Neurological and psychomotor functions in children with an increased lead burden. Environmental Health Perspectives, 7, 13-16.

Registrar General (1970). Classification of Occupations.

Richman, N., and Graham, P. J. (1971). The behavioural screening questionnaire for use with 3 year old children. Journal of Child Psychology and Psychiatry and Allied Disciplines, 12, 5-33.

Smith, H. D., Raehner, R. L., Carney, T., and Majors, W. J. (1963). The sequelae of pica with or without lead poisoning. American Journal of Diseases of Children, 105, 609-616. 